\title{
Life cycle assessment of domestic heat pump hot water systems in Australia
}

\author{
Andrew D. Moore ${ }^{1, *}$, Tania Urmee ${ }^{2}$, Martin Anda ${ }^{2}$, and Elaine Walker ${ }^{2}$ \\ ${ }^{1}$ Life Cycle Logic, P.O. Box 571, Fremantle, WA 6959, Australia \\ ${ }^{2}$ School of Engineering and Information Technology, Murdoch University, Murdoch, WA 6150, Australia
}

Received: 15 January 2017 / Received in final form: 5 July 2017 / Accepted: 27 July 2017

\begin{abstract}
Water heating accounts for $23 \%$ of residential energy consumption in Australia, and, as over half is provided by electric water heaters, is a significant source of greenhouse gas emissions. Due to inclusion in rebate schemes heat pump water heating systems are becoming increasingly popular, but do they result in lower greenhouse gas emissions? This study follows on from a previous life cycle assessment study of domestic hot water systems to include heat pump systems. The streamlined life cycle assessment approach used focused on the use phase of the life cycle, which was found in the previous study to be where the majority of global warming potential (GWP) impacts occurred. Data was collected from an Australian heat pump manufacturer and was modelled assuming installation within Australian climate zone 3 (AS/NZS 4234:2011). Several scenarios were investigated for the heat pumps including different sources of electricity (grid, photovoltaic solar modules, and batteries) and the use of solar thermal panels. It was found that due to their higher efficiency heat pump hot water systems can result in significantly lower GWP than electric storage hot water systems. Further, solar thermal heat pump systems can have lower GWP than solar electric hot water systems that use conventional electric boosting. Additionally, the contributions of HFC refrigerants to GWP can be significant so the use of alternative refrigerants is recommended. Heat pumps combined with PV and battery technology can achieve the lowest GWP of all domestic hot water systems.
\end{abstract}

\section{Introduction}

Traditional electric hot water systems heat water by passing electricity through a resistive element that is immersed inside the water storage tank. Heat pump hot water systems, which are gaining in popularity in Australia, are a different type of hot water system. Rather than using electricity to create heat, these systems use electricity to move (or pump) heat from the environment to the inside of the hot water system [1]. As it can take less energy to move heat than it would to create it using an electric element, heat pumps can be a more efficient method of water heating. However, heat pump hot water systems often use refrigerants to transfer the heat from the environment to the inside of the tank. Ozone-depleting chloroflurocarbons refrigerants have been phased out as part of the Montreal protocol but many have been replaced by synthetic hydroflurocarbons (HFC) refrigerants, such as R410a, which can contribute to climate change if released to the atmosphere. For example, $1 \mathrm{~kg}$ of $\mathrm{HFC}$ refrigerant $\mathrm{R} 410 \mathrm{a}$ released to the atmosphere has the equivalent global warming potential (GWP) of $2088 \mathrm{~kg} \mathrm{CO}_{2} \mathrm{e}[2]$.

\footnotetext{
* e-mail: Andrew@lifecyclelogic.com.au
}

This paper expands on research conducted for the paper "Life cycle assessment of domestic hot water systems in Australia" [3] which compared the GWP of a range of domestic hot water systems in Australia using a streamlined cradle-to-grave life cycle assessment approach. The previous study included five common hot water systems: electric storage, gas storage, gas instantaneous, solar electric thermosiphon, and solar gas instantaneous. Each was sized to meet a medium hot water load within climate zone 3 as defined according to AS/NZS 4234:2011.

Several papers and reports have been published on the greenhouse gas emissions of heat pump hot water systems for other countries [4-8]. Some of these studies, as well as several Australian studies, did not include refrigerant losses $[4,5,7,9,10]$ despite studies showing that refrigerant losses can be significant $[6,8]$.

This paper aims to use a streamlined life cycle assessment approach to investigate whether heat pump hot water systems can result in lower greenhouse gas emissions (i.e. GWP) than traditional hot water systems installed in Australia.

\section{Methodology}

The scope of this study focuses on the greenhouse gas emissions produced during the use phase of the life cycle, which has been shown to be the largest source of emissions 
(87-99\%) for domestic hot water systems [3,4]. Refrigerant losses from leakage and recovery at end of life, which have been shown to be significant, have also been included.

The functional unit of the study was a standardised "medium" annual hot water load of $34.4 \mathrm{MJ} /$ day, which is equivalent to $200 \mathrm{l} /$ day at $60^{\circ} \mathrm{C}$ within climate zone 3 [11], over the assumed 10-year life of the systems.

Two types of heat pump hot water system were modelled based on data provided by a local manufacturer: - heat pump hot water system with a separate standalone hot water storage tank and heat pump module;

- hybrid solar heat pump with flat plate solar thermal collectors and the standalone air-source heat pump independently coupled (in parallel) to the separate hot water storage tank.

The scenarios include electricity sourced from the Australian grid, a grid-tied solar photovoltaic (PV) system, and a solar PV lithium-ion battery system (Fig. 1).

The total electricity consumption of the heat pump hot water systems (including heat pump, fans, circulation pumps, and control systems) was based on tests and TRNSYS modelling to AS/NZS 4234:2011 conducted for locally manufactured heat pump systems $[12,13]$.

HFC R410A is a synthetic hydroflurocarbon greenhouse gas refrigerant commonly used in domestic heat pump hot water systems and air conditioning systems. It has zero ozone depletion potential but a high GWP of $2088 \mathrm{~kg} \mathrm{CO}_{2} \mathrm{e} / \mathrm{kg}$ [2]. An alternative to R410a is Minus 60 (M60) which is a blend of R290 propane $(<60 \%)$, R600a isobutane $(>35 \%)$ and R170 ethane $(>5 \%)[14]$. M60 has zero ozone depletion potential and also a very low GWP of $3.2 \mathrm{~kg} \mathrm{CO}_{2} \mathrm{e} / \mathrm{kg}[2,14]$. The use of both refrigerant types has been included in the study. Refrigerant leakage rates of $9 \%$ annually [15] and refrigerant recovery rate of $85 \%$ [8], at the end of the assumed 4-year life of the heat pump compressor module, were used.

The average Australian greenhouse gas emission factors for electricity (full fuel cycle $0.94 \mathrm{~kg} \mathrm{CO}_{2} \mathrm{e} / \mathrm{kWh}$ ) were taken from the Australian National Greenhouse Accounts, August 2015 [15] to enable comparison with the published results for domestic hot water systems in Australia [3].

The emission factors for the consumption of electricity from solar PV systems in Australia were averaged across Australian capital cities within climate zone 3 of $0.042 \mathrm{~kg}$ $\mathrm{CO}_{2} \mathrm{e} / \mathrm{kWh}$ [16]. The estimated emission factor for a $10 \mathrm{kWh}$ lithium-ion battery was $0.014 \mathrm{~kg} \mathrm{CO}_{2} \mathrm{e} / \mathrm{kWh}$ based on: a 20-year service life [17], $90 \mathrm{~kg} \mathrm{CO}_{2} \mathrm{e} / \mathrm{kWh}^{1}$ of stationary storage [18], and battery round trip efficiency (PV-batterygrid) of $90 \%$ [19].

\section{Results}

The results of the two heat pump hot water systems (Fig. 2) are compared with five conventional hot water systems as previously published [3]. The error bars represent the range of performance that can be expected from variations in efficiency and solar contribution factor. For the heat pump

${ }^{1}$ Including raw material extraction, production, transport, and use life cycle phases.

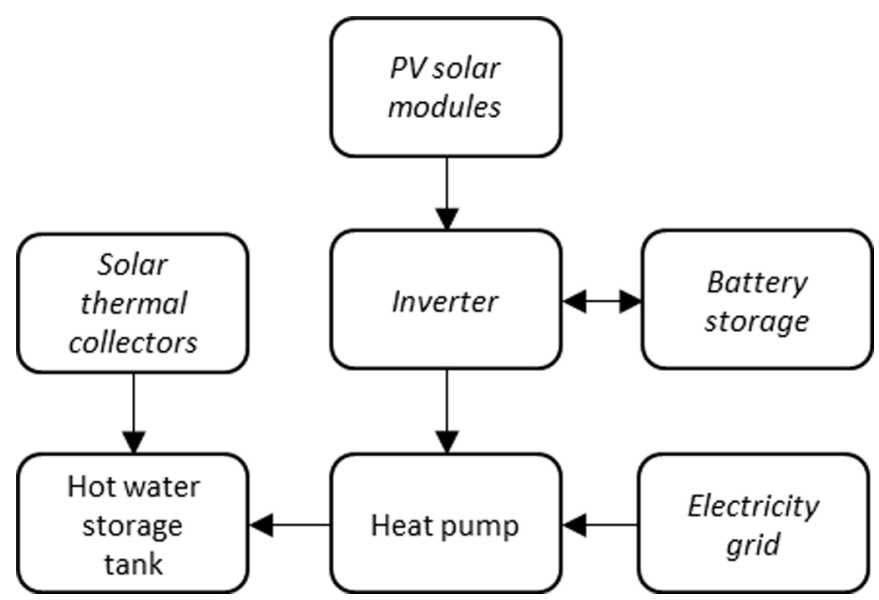

Fig. 1. Configuration of the heat pump hot water system scenarios (optional elements shown in italics).

hot water systems the error bars represent the variation in GWP from using R410a and M60 refrigerants (upper and lower values, respectively).

The overall results indicate that heat pump hot water systems can have a GWP $57 \%$ lower than a conventional electric storage hot water system. The results for the solar heat pump (grid) demonstrate that the addition of two solar thermal collectors ${ }^{2}$ can further reduce the GWP by $14 \%$ to achieve an overall reduction of $71 \%$ compared to the electric storage system. A solar heat pump hot water system can also have $30 \%$ lower GWP compared to a solar electric hot water system that has a $60 \%$ solar contribution factor. The gas instantaneous system had similar GWP to the solar heat pump. The solar gas instantaneous system had the lowest GWP overall under these initial scenarios.

Refrigerant losses (fugitive and recovery) are estimated to account for between $11 \%$ and $16 \%$ of the GWP for the two heat pump hot water systems. The GWP associated with the use of HFC refrigerants such as R410a can almost be eliminated (99.8\% reduction) by the use of alternative refrigerants such as M60.

Figure 3 presents the results for the six different heat pump hot water system scenarios (primary/secondary electricity sources shown in brackets). The scenario with the highest GWP is scenario 1, heat pump (grid), which uses average Australian grid electricity to power the heat pump. Scenario 2, heat pump (grid/PV), uses a PV system (rather than solar thermal collectors) to heat water using solar energy. In this scenario the PV system has been sized to provide the same solar contribution as the solar thermal collectors in scenario 4 (see additional information in footnote 2). The

${ }^{2}$ The $34 \%$ reduction in energy consumption achieved by the solar heat pump system (which uses $3678 \mathrm{MJ} /$ year) compared to the heat pump with no solar (5826 MJ/year), as reported in Vipac Engineers and Scientists Ltd. [12], is significantly lower than the $60 \%$ (9156 MJ/year) expected for typical hot water systems [11]. The control strategy of the heat pump (which turns on the heat pump from 12 midnight -7 am, $11 \mathrm{am}-2 \mathrm{pm}$, and $4 \mathrm{pm}-7 \mathrm{pm}$ ) potentially reduces the contribution that the solar thermal collectors can provide (i.e. the water has already been heated for $7 \mathrm{~h}$ between 12 midnight and 7 am before the sun can rise and heat the solar collectors). Therefore, it may be possible to achieve greater energy and GWP reductions than indicated. 


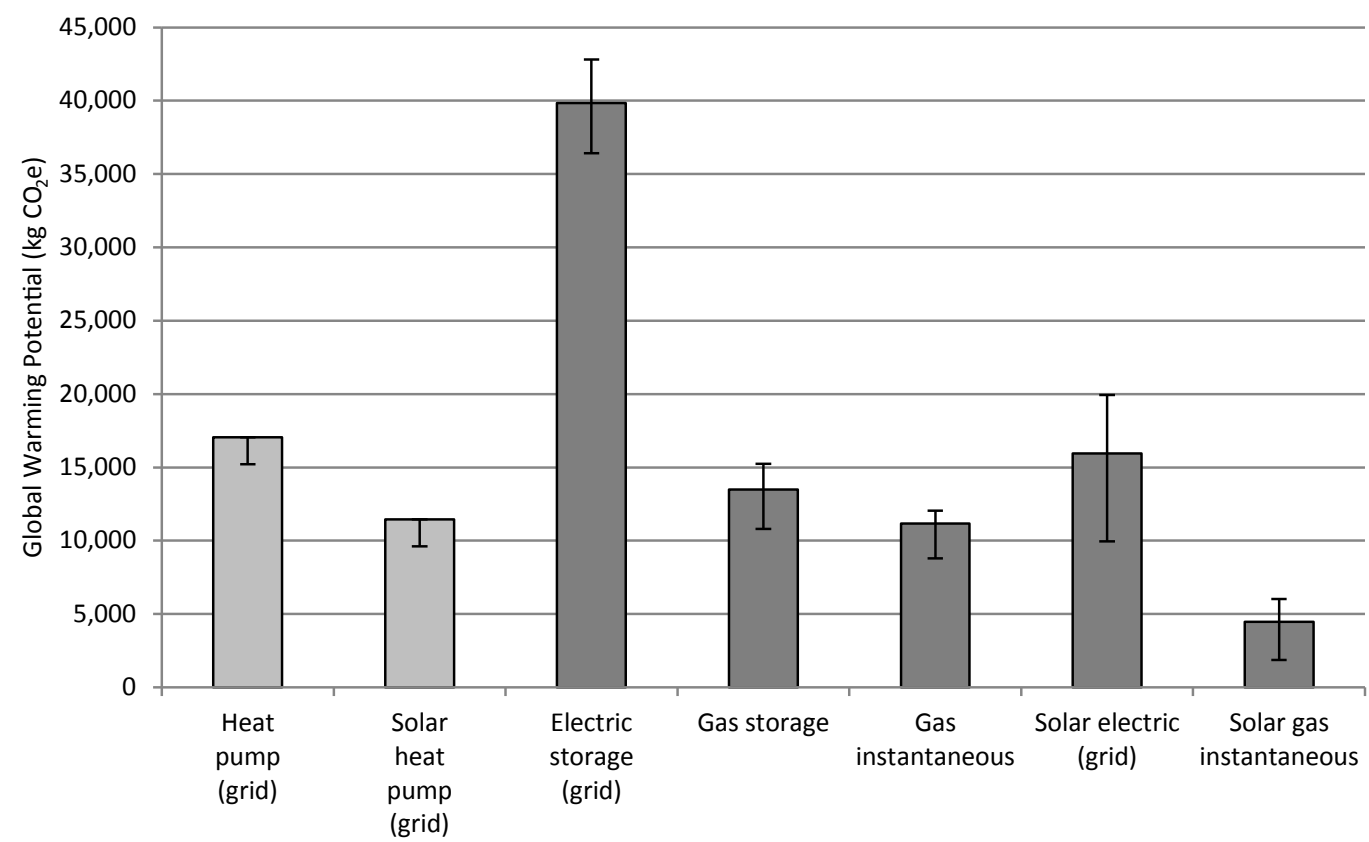

Fig. 2. Comparison of global warming potential for two heat pump systems and five conventional domestic hot water systems including use phase and refrigerant losses (dark grey results from Moore et al. [3]).

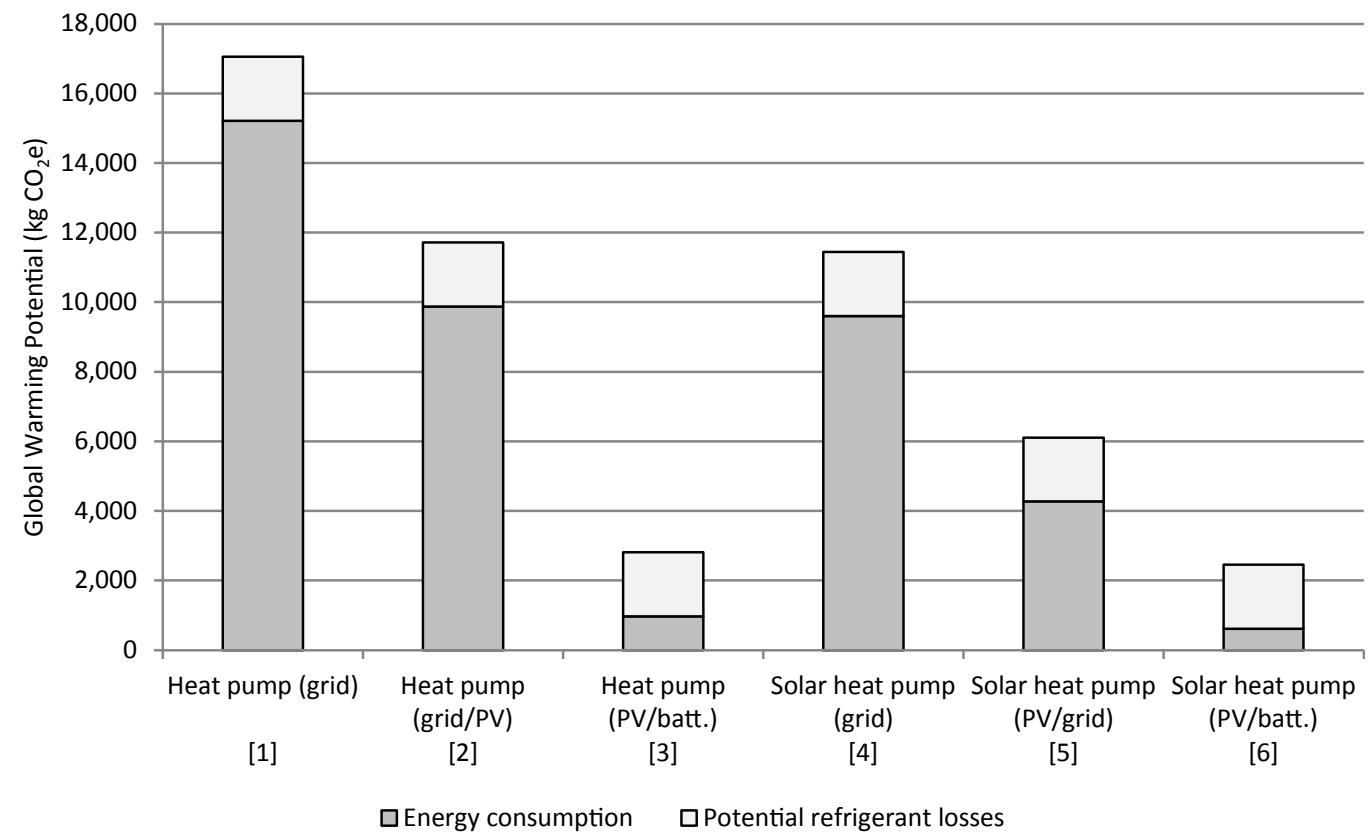

Fig. 3. Comparison of GWP for different heat pump scenarios (primary/secondary energy sources shown in brackets).

results indicate that despite the higher embodied GWP associated with the use of PV compared to solar thermal collectors the overall GWP results are similar. This is due to the grid being the primary source of electricity for both.

\footnotetext{
${ }^{3}$ Heat Trap Solar Pty Ltd., personal communication, May 2016.

${ }^{4}$ Assuming installation of the PV system in the capital city within climate zone 3 that has the lowest electricity production of $3.9 \mathrm{kWh} / \mathrm{kWp}$ - Sydney [21], $20^{\circ}$ inclination and $45^{\circ}$ azimuth, heat pump annual average coefficient of performance (energy consumed to hot water out) of 2.2 .
}

The use of a PV system, rather than solar thermal collectors, can simplify the installation process as plumbing of the collectors to the tank is not required. Based on the current energy consumption data (see footnote 2 ), the use of $\mathrm{PV}$ rather than solar thermal collectors may also be a more cost effective option. The added cost of $\$ 1200$ to supply and install solar thermal collectors on the roof ${ }^{3}$ could alternatively be used to purchase $0.9 \mathrm{kWp}$ of $\mathrm{PV}$; inclusive of PV modules, inverter, taxes, rebates, and installation [20]. Only $0.5 \mathrm{kWp}^{4}$ (or two $250 \mathrm{~W}$ solar PV modules) would be required to provide the same annual energy that 
the two solar thermal collectors are currently modelled to provide when combined with the added efficiency of the heat pump.

The use of PV and batteries (scenarios 3 and 6) can theoretically result in GWP lower than even the most efficient solar gas instantaneous hot water systems.

\section{Conclusions and recommendations}

Due to their higher efficiency, heat pump hot water systems can result in significantly lower GWP than electric storage hot water systems. Solar heat pump systems can have lower GWP than solar electric hot water systems that use conventional electric boosting. The contributions of HFC refrigerants to GWP can be significant so the use of alternative refrigerants is recommended. Heat pumps combined with PV and battery technology can achieve the lowest GWP of all domestic hot water systems.

Based on the findings of this study, it is recommended that to reduce GWP associated with the use of domestic hot water systems heat pump hot water systems be used in place of conventional electric storage hot water systems. Recommendations for further research include:

- revising the study to include updated TRNSYS modelling results (when conducted) that include the improved control system and increased heat pump efficiency gains through the use of M60 refrigerant;

- confirming initial findings with detailed time-of-use simulations for solar PV production, battery utilisation, seasonal heat pump load, and seasonal hot water load;

- carrying out a full life cycle assessment to identify where other environmental performance improvements can be made. This is recommended because as the shift to renewable energy electricity sources occurs the embodied GWP in the materials used becomes more significant;

- LCA that compares different space heating/cooling systems coupled to the optimum solar PV heat pump. New 3-in-1 heat pump systems can be compared with separate reverse-cycle split air-conditioning for a given house energy efficiency rating and hydronic floor heating.

Thanks to Heat Trap Solar Pty Ltd. and Murdoch University for funding this study.

\section{References}

1. J.A. Duffie, W.A. Beckman, Solar Engineering of Thermal Processes, 2nd edn. (Wiley, New York, 1991)

2. Linde Group, Refrigerants Environmental Data (Linde Ind Gases, 2016), http://www.linde-gas.com/en/products_and supply/refrigerants/natural_refrigerants/index.html (accessed on: 2016/05/12)

3. A.D. Moore, T. Urmee, P.A. Bahri, S. Rezvani, G.F. Baverstock, Life cycle assessment of domestic hot water systems in Australia, Renew. Energy 103, 187 (2017)
4. A. Genkinger, R. Dott, T. Afjei, Combining heat pumps with solar energy for domestic hot water production, Energy Proc. 30, 101 (2012)

5. C. Chiavetta, F. Tinti, A. Bonoli, Comparative life cycle assessment of renewable energy systems for heating and cooling, Proc. Eng. 21, 591 (2011)

6. S. Eicher, C. Hildbrand, A. Kleijer, J. Bony, M. Bunea, S. Citherlet, Life cycle impact assessment of a solar assisted heat pump for domestic hot water production and space heating, Energy Proc. 48, 813 (2014)

7. B. Hong, R.W. Howarth, Greenhouse gas emissions from domestic hot water: heat pumps compared to most commonly used systems, Energy Sci. Eng. 4, 123 (2016)

8. A. Zottl, M. Lindahl, R. Nordman, P. Rivière, M. Miara, Evaluation method for comparison of heat pump systems with conventional heating systems - concept for evaluation of $\mathrm{CO}_{2}$-reduction potential (2011)

9. Wilkenfeld and Associates, Estimated Household Water Heater Energy Use, Running Costs and Emissions (Sustainable Energy Authority Victoria, Victoria, 2005)

10. Sustainability Victoria, Estimated Hot Water System Running Costs in Victoria, Victoria (2010)

11. Standards Australia, AS/NZS 4234:2008/Amdt 2:2011 Heated Water Systems - Calculation of Energy Consumption (2011)

12. Vipac Engineers and Scientists Ltd., TRNSYS Modelling for Heat Pump and Solar Water Heaters to CER Guidelines: STC Assessment of HTS-340, Melbourne, Australia (2012)

13. Vipac Engineers and Scientists Ltd., TRNSYS Modelling for Heat Pump and Solar Water Heaters to CER Guidelines: STC Assessment of HTS340-CP, Melbourne, Australia (2013)

14. HyChill Australia, HyChill-Minus 60 (2016), https://hychill. com.au/products/minus-60 (accessed on: 2016/09/08)

15. Department of Environment, National Greenhouse Accounts (NGA) Factors (Commonwealth of Australia, August 2015)

16. Moore, Life Cycle Assessment (LCA) of a Solar Photovoltaic System Installed in Australia and New Zealand, Wellington, New Zealand (2010)

17. Fronius International GmbH, Products - Fronius System Solutions (2016), http://www.fronius.com/cps/rde/xchg/ SID-6F83DBE3-EA3A97AA/fronius international/hs.xsl/ 8335481 ENG HTML.htm\#.WFjX̄XUVN971o (accessed on: $2016 / \overline{20} / 12$ )

18. K. Ishihara, N. Kihira, N. Terada, T. Iwahori, Environmental Burdens of Large Lithium-Ion Batteries Developed in a Japanese National Project (Cent. Res. Inst. Electr. Power Ind., Japan, 2002)

19. Fronius International GmbH, Products - Grid-Connected Inverters, n.d., http://www.fronius.com/cps/rde/xchg/SID47B93AD8-95F14BAC/fronius_international/hs.xsl/ 83_35331_ENG_HTML.htm\#.WFI1XbJ971o (accessed on: $2016 / \overline{15} / 12$ )

20. Solar Choice, Residential solar PV system prices for December 2016 (2016), http://www.solarchoice.net.au/ blog/news/residential-solar-pv-system-prices-december2016 (accessed on: 2016/16/12)

21. National Renewable Energy Laboratory, System Advisor Model Version, Golden, $C O(2016)$ (accessed on: 2016/31/10)

Cite this article as: Andrew D. Moore, Tania Urmee, Martin Anda, Elaine Walker, Life cycle assessment of domestic heat pump hot water systems in Australia, Renew. Energy Environ. Sustain. 2, 38 (2017) 